\title{
Diagenesis and reservoir quality of the Lower Permian ignimbrite in the Sichuan Basin, China
}

\author{
WEI WANG ${ }^{1}$ \\ ${ }^{1}$ PetroChina Southwest Oil \& Gas field Company, \\ Chengdu 610051, China ww881211@126.com
}

The Lower Permian ignimbrite in the southern Sichuan Basin is the typical volcanic reservoir in China. On the basis of a large number of cores and thin-sections observations, the petrologic and pore evolution characteristics of ignimbrite are studied. The reservoir porosity is relatively high (average $15.4 \%$ ) but permeability is quite low (average $0.226 \mathrm{mD}$ ). The ignimbrite reservoir has undergone significant diagenetic alteration such as plastic shards devitrification, pyroxene dissolution, carbonate cementation, feldspar dissolution and chlorite cementation. As to the onset time, the gas emplacement was prior to the carbonate and chlorite cementation but posterior to plastic shards devitrification and feldspar dissolution. The plastic shards devitrification and pyroxene dissolution provide a most important magnesium and iron source for chlorite cementation. Chlorite cementation narrowed throats and reduced permeability significantly. However, chlorite preserved the porosity since it tends to be oil wet so that later carbonate cementation can be inhibited to some extent. It is likely that gas emplacement occurred earlier than those throats destruction. Indeed, the ignimbrite reservoir in the study area can effectively preserve natural gas. 